\section{Saberes e práticas da docência em \\ hospital: vivências do pedagogo \\ em formação através da extensão universitária}

\section{Francy Sousa Rabelo}

Professora e pesquisadora da

Universidade Federal de Maranhão, Brasil.

francy.rabelo@ufma.br
Integración de la docencia y la extensión /

Intervenciones

RECEPCIÓN: 16/06/16

ACEPTACIÓN FINAL: 23/09/16

\section{Resumo}

Este texto investigou a relação dos saberes e práticas da docência na formação inicial vivenciada no projeto de extensão "Estudar, uma ação Saudável". O referido projeto se desenvolve no Hospital Universitário da Universidade Federal do Maranhão com atividades educativas para crianças hospitalizadas. Utiliza na pesquisa, o método de estudo de caso e a entrevista semiestruturada como instrumento de coleta de dados e teve como público alvo, as alunas do curso de Pedagogia da Universidade Federal de Maranhão, participantes do projeto. A pesquisa mostrou que a extensão universitária favorece a formação inicial, novos espaços de atuação já previsto nas Diretrizes Curriculares Nacionais para o Curso de Pedagogia, evidenciou que os saberes docentes foram reelaborados e construídos pelas alunas/professoras de acordo com suas experiências de ensino e a relação com o espaço hospitalar para o benefício das crianças hospitalizadas.

Palavras-chave

- Extensão Universitária

- Formação inicial

- Hospital

- Saberes da Docência

\section{Resumen}

El texto buscó comprender la relación de los saberes y prácticas de la docencia en la formación inicial vivenciada en el proyecto de extensión "Estudiar, una acción saludable" desarrollado en el Hospital Universitario de la Universidad Federal de Maranhão - HUUFMA con actividades educativas para los niños hospitalizados. La investigación utiliza el método de estudio del caso y la entrevista semiestructurada como instrumento de recolección de datos y tuvo como público destinatario a las alumnas de la carrera de Pedagogía de la Universidad Federal do Maranhão, participantes del proyecto. La investigación mostró que la extensión universitaria favorece la formación inicial del pedagogo, nuevos espacios de acción, según lo explicado en los Lineamientos Curriculares de la carrera de Pedagogía. El estudio reveló que los conocimientos docentes adquiridos en el proceso de formación han sido actualizados y construidos por los estudiantes de acuerdo con sus experiencias de enseñanza y en las relaciones con el espacio hospitalario para beneficio de los niños hospitalizados.

Palabras-clave

- Extensión Universitaria

- Formación inicial

- Hospital

- Saberes de la docencia
Para citación de este artículo

Sousa Rabelo, F. (2016). Saberes e práticas da docência em hospital: vivências do pedagogo em formação através da extensão universitária. En Revista +E versión digital, (6), pp. 314-319. Santa Fe, Argentina: Ediciones UNL. 


\author{
há, para o profissional da Pedagogia, \\ o desafio de uma nova forma de \\ atuação pedagógica que leva em conta \\ a complexidade do sujeito em estado \\ de hospitalização
}

\section{Introdução}

A possibilidade da inserção do pedagogo no âmbito da educação não escolar é explícita nas Diretrizes Curriculares Nacionais de seu curso. Tal vivência ainda se faz de maneira escassa na formação inicial dos pedagogos na Universidade Federal do Maranhão (UFMA), contudo, esta tem sido alcançada quando os alunos participam de experiências extensionistas, das tais se exemplifica o projeto de extensão Estudar, uma ação saudável desenvolvido no Hospital Universitário da Universidade Federal do Maranhão (HUUFMA), cuja experiência gerou a pesquisa aqui apresentada. Com tal exigência em sua diretriz curricular, há, para o profissional da Pedagogia, o desafio de uma nova forma de atuação pedagógica que leva em conta a complexidade do sujeito em estado de hospitalização. Consequentemente, o preparo do professor/ pedagogo para atender as questões inerentes à escolarização de crianças e adolescentes hospitalizadas é imprescindível.

A legislação brasileira (Brasil, 2002), atualmente, reconhece o atendimento pedagógico educacional como direito das crianças e adolescentes, quando estão hospitalizadas. Autores como Fonseca (2003), Matos e Mugiatti (2007) tratam dessa questão, embora destaquem que o fazer docente neste ambiente requer peculiaridades no tocante a atividade desenvolvida a respeitar os limites destes sujeitos. Por isso, a formação do professor especialmente em cursos de Pedagogia, agentes principais da Educação Infantil e dos Anos Iniciais do Ensino Fundamental, devem ocupar-se de suas atribuições com a educação não escolar, não apenas como foco do debate acadêmico, mas como conteúdo do seu projeto formativo, uma vez que entende-se que neste processo, as relações entre pesquisa, ensino e extensão devem formar um conjunto de saberes que corroboram com a formação acadêmica. Contudo, tal projeto formativo na UFMA aponta as relações entre pesquisa e ensino com ênfase na escola regular como campo de estudo e lócus específico da atuação deste profissional.

O estudo aqui apresentado visa investigar a relação dos saberes e práticas da docência em espaço hospitalar na formação inicial a partir da vivência na extensão universitária. O presente estudo é resultado de uma dissertação de mestrado defendida no ano de 2014, que analisou o projeto de extensão "Estudar, uma ação saudável" desenvolvido no Hospital Universitário da Universidade Federal do Maranhão. Tal projeto de extensão iniciado em 2007 e perdura até os dias atuais, desenvolve-se com alunas e alunos do curso de pedagogia da UFMA cujo objetivo é proporcionar as crianças hospitalizadas no referido hospital, o direito ao acompanhamento do currículo escolar.

Este estudo se ancora na abordagem de pesquisa qualitativa e usou como método de procedimento, o estudo de caso com base nos autores Yin (2010) e Stake (2007) porque defendem que o objeto de análise deve retratar uma situação da vida real, neste caso, a docência das alunas em um hospital, quando estavam em processo de formação inicial no Curso de Pedagogia da Universidade Federal do Maranhão-UFMA. Para coletar os dados juntos aos sujeitos pesquisados utilizou-se da entrevista semiestruturada (Szymanski, 2011), para apresentar o entendimento das alunas acerca de seus saberes e práticas constituídos e utilizados na ação docente no hospital.

\section{Formação Inicial do Pedagogo e Extensão Universitária: relação que produz saberes e práticas diferenciadas} As Diretrizes Nacionais para o Curso de Pedagogia (Brasil, 2006) marcam os desafios da contemporaneidade na atuação do pedagogo, alcançando além dos espaços escolares, as crianças que estão fora da escola formal. Desta feita, aponta-se para as discussões a respeito do processo de inclusão social. Nesta perspectiva, para alcançar o direito à educação, o atendimento pedagógico no hospital se apresenta como uma estratégia diferenciada, ou seja, a de alterar o dia-a-dia da internação das crianças e proporcionar uma maior humanização e interação social, assim como dar continuidade ao aprendizado dos conteúdos 
escolares vedados com a internação, pois segundo Matos e Mugiatti (2007) relatam que

"a criança e o adolescente, nessa fase, se encontram em pleno período de aprendizagem, que estão eles ávidos por novidades, essas operadas pela observação, experiência e comunicação, elementos constitutivos da aprendizagem em condições permanentes". (p.28)

Indubitavelmente, a ruptura da rotina escolar produz desconfortos e pode prejudicar os estudantes na sua volta à escola e quiçá até motivar o afastamento definitivo dela, com vistas ao direito a educação destes, cabe questionar, como os cursos de Pedagogia tem discutido sobre os espaços não escolares, aqui destacado pelo hospital. No caso da UFMA, tal discussão se efetiva pela extensão universitária e esta vem produzindo história na formação inicial, como aponta Gurgel (1986), ela surge no Maranhão como bandeira de lutas pelos estudantes. Dessa forma, é nesta bandeira de luta pelo direito a educação da criança e adolescente hospitalizados que no curso de Pedagogia da UFMA tem sido o fator para envolver os alunos para além dos muros acadêmicos e, principalmente, a relação com a educação não escolar. A defesa da extensão universitária na formação inicial promove uma universidade que ultrapasse seus muros e esteja a serviço da sociedade, isto posto a extensão defendida por Gurgel se ancora em Freire (1980, p.36) em que o conhecimento na extensão advém da troca e não "se estende do que se julga sabedor até aqueles que se julga não saberem; o conhecimento se constitui nas relações homem".

Nesta perspectiva, a contribuição se dá no processo de construção de conhecimento que se efetiva pelo diálogo, logo, ser dialógico, segundo o autor, não é invadir, é empenhar-se na transformação constante da realidade.

É portanto, nas relações que as intervenções do pedagogo realizadas no hospital pela via da extensão universitária podem promover o bem-estar das crianças enfermas, provocando ainda, a possibilidade de retorno às salas de aula das classes regulares de ensino. Taam (2004) menciona que o mais importante nesse contexto não é adaptar o modelo escolar ao hospital, mas de surgirem modelos de atuação pedagógica que identifiquem as características do ambiente hospitalar e da posição existencial da criança real, aquela que está perante o outro com todos os seus casos de vida.

Dessa forma, o tempo de internação vivido pela criança no hospital é modificado por um período de aprendizagem, de construção de saberes e aquisição de novos conceitos proporcionados pelo atendimento pedagógico que se fez pela extensão universitária, uma vez que as políticas sociais e educacionais ainda não garantiram neste espaço, o direito a educação no hospital, fator já existente em outros estados do Brasil.
2.1. O projeto de extensão Estudar uma ação saudável, uma intervenção em favor da criança hospitalizada O projeto de extensão investigado surge no ano de 2007 por solicitação do Hospital Universitário da Universidade Federal do Maranhão ao Departamento de Educação I da UFMA para desenvolver atividades lúdicas e pedagógicas com crianças ali hospitalizadas, contudo sua aprovação se faz apenas em 2009, sob a Resolução 665 CONSEPE- Conselho de Ensino, Pesquisa e Extensão da UFMA. Sua atuação conta com a participação de alunas do curso de Pedagogia, sob a orientação das coordenadoras e professoras daquela universidade e acompanhadas pela pedagoga do hospital. O projeto visa criar possibilidades de reinserção das crianças e adolescentes em situação de adoecimento, na escola em nivel de Educação Infantil e Ensino Fundamental e também possibilitar a reflexão junto aos alunos do Curso de Pedagogia, a necessidade do pedagogo de se aproximar de espaços não escolares para desenvolvimento de atividades pedagógicas.

A intervenção extensionista no hospital provoca mudanças em sua rotina, uma vez que se disponibiliza espaço específico para o desenvolvimento da ação docente, fator diferenciado das atividades diárias daquela instituição. Tais intervenções se desenvolvem com atividades pedagógicas por projetos de trabalhos que envolvam conteúdos escolares, cujos resultados são apresentados em relatórios entregues aos responsáveis dos hospitalizados no momento da alta.

Além das atividades de ensino, a extensão provoca na formação docente reflexões sobre a prática pedagógica em espaço não escolares, que geram pesquisas divulgadas em trabalhos científicos, 17 monografias e 02 dissertações de mestrado. Esta articulação entre ensino, pesquisa e extensão promoveu conforme as referidas pesquisas, um diálogo humanizado através do olhar para o outro, no intuito de compreendê-lo em suas circunstâncias de hospitalizado. Em Freire (1980), entende-se esse diálogo como um "encontro amoroso dos homens que, mediatizados pelo mundo, o 'pronunciam', isto é, o transformam, e, transformando-o, o humanizam para a humanização de todos" (p.43). Este encontro é promovido pela extensão universitária na formação do pedagogo, porque não houve invasão cultural, manipulação, mas troca de saberes produzidos nesta articulação, mediadas pela flexibilização curricular na medida em que alunas e professoras/coordenadoras estudaram e divulgaram o espaço hospitalar como mais um campo de produção de saberes do pedagogo.

Na educação não escolar sabe-se que há flexibilização do currículo para que as ações educativas sejam pensadas e realizadas a atender as especificidades da classe no hospital, tal classe tem por característica, crianças com faixas etárias diferenciadas e patologias diversas. Diante desta complexidade, a prática docente é desafiadora, por isso vai se fundamentar no desenvolvimento de 


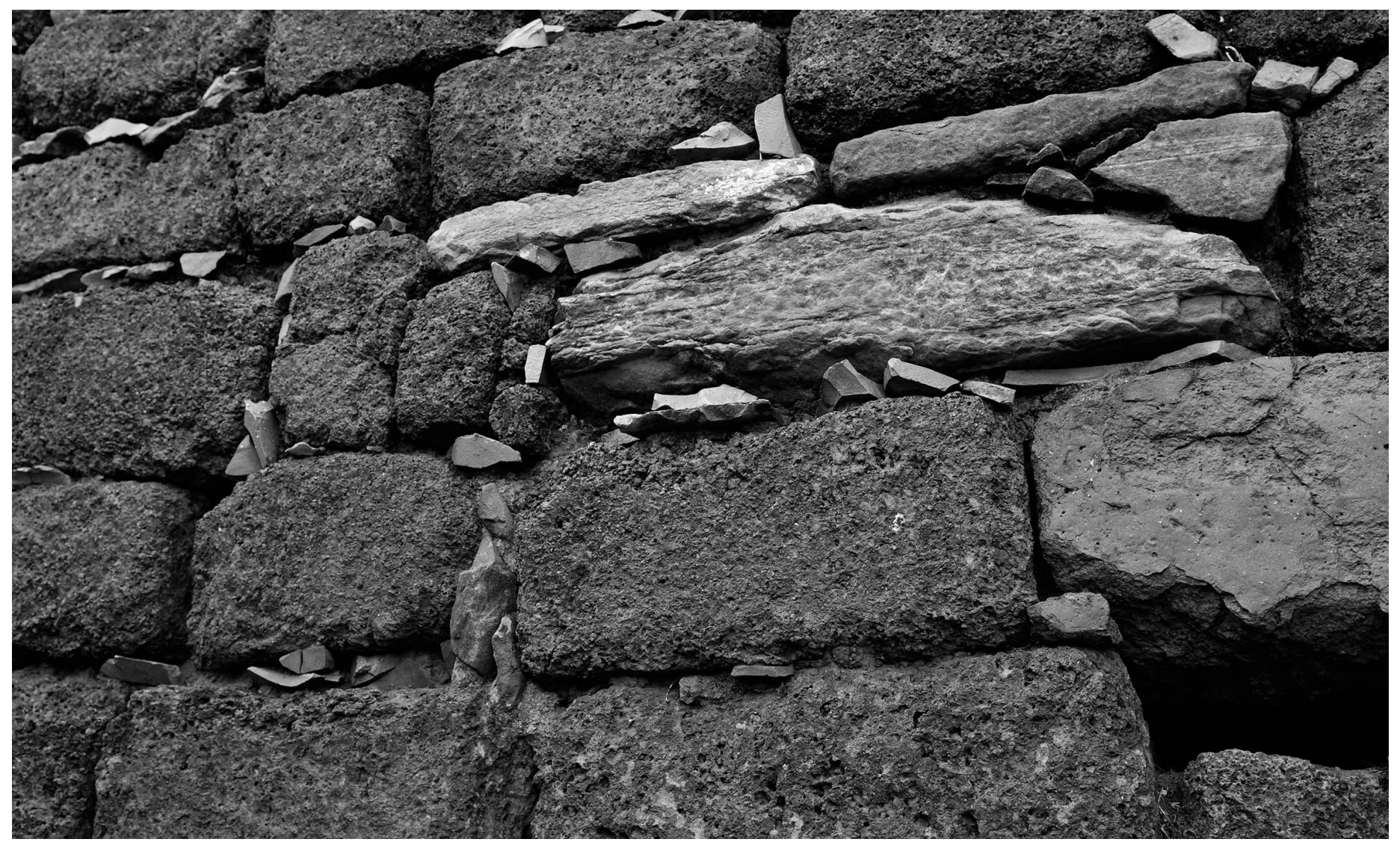

(c) Oscar Dechiara

saberes experienciais, e também proporcionar uma avaliação dos demais saberes, principalmente os disciplinares e pedagógicos adquiridos na formação profissional segundo Pimenta (2009). Para Tardif (2010), esse momento se faz através de sua retradução, ou seja, a experiência docente promove a oportunidade de reorganizar seus saberes para adaptá-los no contexto em que se insere, podendo ser inovados e abalizados por novos conhecimentos. A experiência torna-se inovadora para o ambiente hospitalar, uma vez que a prática das alunas pesquisadas era convocada pelos enfermeiros e psicólogos deste espaço para atender crianças com o uso da intervenção pedagógica, no período pós-cirúrgico, o que denota uma relação promissora entre saúde e educação.

Os dados da pesquisa denotam que nas intervenções dos sujeitos se alicerçam os saberes da formação profissional que provocam um novo olhar para a aula, porque esta não começa na sala, mas nas relações com as crianças e com os demais, relação que é fator vivenciado na extensão universitária, que se sustenta em Freire (2006) quando diz que precisa-se quebrar a verticalidade "coisificadora", onde um ator é sujeito e o outro objeto, e promover uma relação onde todos possam ser sujeitos atuantes, que agem e pensam criticamente, então os saberes aqui produzidos pela extensão universitária na vivência no hospital, superam os conteúdos a serem construídos pelos alunos/pacientes e avançam para uma troca coletiva pelo diálogo, em que o espaço com toda a sua complexidade vai se descortinando e transformando-se em um hospital/escola.

A necessidade de conhecimentos específicos incorporados para um melhor desenvolvimento da prática das alunas no hospital está presente em suas declarações, quando enfocam a questão doença, porque se acredita que, pela internação, há uma intimidação ao seu modo de viver e a sua rotina, daí a necessidade de saberes que devem ser mobilizados e utilizados pela aluna/professora em sua ação docente no hospital; contudo, é preciso ser antes de tudo um mediador das interações da criança com o ambiente hospitalar. Por isso, segundo Fonseca (2003) "não lhe deve faltar noções sobre as técnicas terapêuticas que fazem parte da rotina da enfermaria, sobre as doenças que acometem seus alunos" (p.29). A relação entre aluna /professora e aluno/paciente deve levar em conta todos esses elementos, o espaço precisa ser conhecido, a doença precisa ser compreendida, não numa perspectiva da Medicina, mas como elemento que subsidie a prática docente. Esta afirmação também é confirmada por outra egressa do curso 


\section{o mais importante nesse contexto não \\ é adaptar o modelo escolar ao hospital, mas de surgirem modelos de atuação pedagógica que identifiquem as características do ambiente hospitalar e da posição existencial da criança real}

e participante do projeto (Castro, 2011), que em sua pesquisa monográfica, disserta acerca do mesmo, quando diz que é preciso que

"o pedagogo não se limite simplesmente às teorias $\mathrm{e}$ conhecimentos específicos do curso de Pedagogia, mas amplie e faça desenvolver sua formação, recebendo e buscando conhecimentos e informações indispensáveis para lidar com as patologias e limitações dos alunos/pacientes enfermos". (p.80)

A atuação docente das alunas no hospital requer novos conhecimentos, além dos básicos adquiridos nas disciplinas do Curso de Pedagogia da UFMA. Tais conhecimentos podem advir tanto no Núcleo Temático de Educação Especial, quanto em Estudos Diversificados, ambos estão postos no projeto pedagógico do referido curso e podem portanto, auxiliá-las em sua na prática pedagógica no que tange a relação educação e saúde. Porém, tal estudo, na nova proposta, ainda não teve sua oferta garantida, visto que os estudos diversificados dependem da demanda dos alunos, em requererem tal disciplina.

Reconhecem as entrevistadas a importância da produção de saberes docentes na extensão universitária a partir das vivências em espaço hospitalar como fundamentos do tornar-se professora. Apontam que os saberes que as tornam professoras são adquiridos na formação universitária e que no espaço hospitalar desenvolvem uma sensibilidade e uma atenção mais aguçada para o sujeito aluno, olham para as necessidades vivenciadas, por isso se tornam mais solidárias, mais companheiras, além de adquirirem o respeito à criança em seu momento de querer aprender. Dessa forma, percebe que a extensão universitária proporcionou as alunas, experiências em espaços não escolares e que tal espaço, com destaque para o hospital, as tornam mais sensíveis. Esta sensibilidade se dá pelo relacionamento que acontece entre alunas/ professora e aluno/paciente, por isso, é necessário compreender o papel das emoções e dos afetos como um instrumento na construção do processo de ensino e de aprendizagem, que para Branco (2008) são precisamente "as reações emocionais que devem constituir a base do processo educativo" (p.67). Saber lidar com as emoções é um saber adquirido na vivência da docência no ambiente hospitalar, pois segundo Taam (2004),

"antes de lidar com as emoções do outro é preciso saber lidar com as suas, é preciso assumir o que se sente, para que a ação pedagógica não seja apenas algo que faça sentir melhor, a si próprio". (p.28)

Nesta vivência, as alunas pesquisadas não apenas mobilizaram saberes que constituem a prática docente, mas produziram conhecimentos que promoveram mudança em seu interior, o que as fez sentirem-se mais humanizadas, condição necessária na evolução do ser humano, sempre inacabado. Para este entendimento, Freire (2008) auxilia que humanizar-se é querer "ser mais", e a "condição humana fundante da educação é precisamente a inconclusão do ser histórico de que nos tornamos conscientes". (p.143)

Essa humanização a que as alunas se reportaram é própria da inconclusão defendida por Freire (2008), quando diz que a formação de ser professor não se limita e nem se esgota, muito menos a educação que gera a prática educativa podendo ser desenvolvida em qualquer campo, pois segundo seus relatos, a vivência pela extensão universitária no espaço diferenciado da escola promove a enxergar outros âmbitos educacionais. No exercício da intervenção no hospital, uma das alunas pesquisadas que já tinha experiência docente por conta de outra graduação, relata que despertou a escuta para a criança/aluno, uma vez que diante do cotidiano docente regular da qual a aluna pesquisada estava acostumada, havia esquecido, pois já não escutava mais o ecoar das vozes de seus alunos em sua sala de aula regular; no hospital desenvolveu uma sensível escuta que superou a voz audível para os olhares e expressões das crianças. Este ouvir refere-se à captação das sensações do outro, por isso a entrevistada diz que no exercício da docência se tornou mais humilde, bem como contribuiu para entender em determinados momentos, uma passividade por parte de quem ensina para dar a voz à criança que, muitas vezes, tem necessidade de falar sobre sua doença. Logo a escuta pedagógica, segundo Fontes (2005), 
é uma forma de trabalhar com a emoção e a linguagem para melhorar a autoestima do doente.

Percebe-se uma ampliação na formação docente desta aluna pesquisada, cuja experiência já era exercida antes do Curso de Pedagogia. O saber destacado por ela, é o saber experiencial, porque possui a característica de saber existencial que, conforme Tardif (2010) está ligado não somente a experiência do trabalho, mas também a história de vida do professor ao que ele foi e o que ele é. Estes saberes foram reformulados no fazer-se pedagogo no novo ambiente de trabalho, houve uma superação dos antigos saberes, uma mudança física e de relações pessoais, portanto trazendo, conforme o autor, outra característica deste saber, a do saber interativo mobilizado e modelado no âmbito de interações entre o professor e outros atores educativos.

As intervenções pedagógicas vivenciadas pela alunas através da extensão universitária no hospital proporcionou situações complexas que na escola regular, espaço legitimado pelo currículo do curso de Pedagogia da UFMA, não se experimentaria, consequentemente os saberes construídos neste processo inexistiriam.

\section{Considerações finais}

Extensão é um movimento idas e vindas, da academia à sociedade e nestas travessias há construção de conhecimentos, docentes e discentes geram aprendizados submetidos a reflexão teórica que será acrescido àqueles conhecimentos.

Nesta investigação pela via da extensão os resultados apontam limitações na formação inicial do pedagogo especificamente aos campos de atuação do pedagogo além da escola e demonstra o papel da extensão universitária como um suporte na formação docente porque supera o distanciamento da atuação deste profissional para outros espaços. Também, a partir das falas das participantes da pesquisa é notório que a experiência vivenciada pela extensão produziu saberes relacionados ao campo de sua atuação, como os saberes experienciais, que mobilizaram os saberes disciplinares e os da formação profissional e deram sustentação ao exercício docente no hospital.

O estudo ressalva a importância da extensão universitária no processo formativo de profissionais, porque a relação com a comunidade e com o outro é estreitada e torna-se elemento fundante na compreensão do seu fazer. Por fim, a constituição de saberes da prática se aperfeiçoa quando as alunas/professoras buscam solucionar problemas oriundos da realidade vivida. Estes saberes são produzidos no fazer-se professor no ambiente de trabalho, mas também pode partir da sua formação em andamento, a exemplo. Portanto, a competência deste fazer tem raízes nas vivências extensionistas, e assim o docente age e, ao agir, elabora saberes produzidos pela sua prática.

\section{Referências Bibliográficas}

Branco, R. F. G. R. (2008). "Capacitação de professores de Classe Hospitalar em relação professor-aluno/paciente na perspectiva balintiana". Tese de Doutorado em Educação não publicada. UFGO. Goiânia-GO.

Castro, N. D. de (2011). "A humanização na dimensão da ação afetiva no atendimento pedagógico hospitalar infantil”. Tese de Licenciatura não publicada. UFMA. São Luis.

Conselho Nacional de Educação (2006). "Institui Diretrizes Curriculares para o Curso de Graduação em Pedagogia, licenciatura". Resolução CNE/CP No 1, de 15 de Maio de 2006. Brasília: Conselho Nacional de Educação.

Fontes, R. (2005). "A escuta pedagógica à criança hospitalizada: discutindo o papel da educação no hospital”. Revista Brasileira de Educação. pp.119-139. Maio /Jun /Jul /Ago

Fonseca, E. S.(2003). Atendimento escolar no ambiente hospitalar. São Paulo: Memnon.

Freire.P. (1980). Extensão ou comunicação? Rio de Janeiro, Brasil: Paz e Terra. Freire, P. (2008). Pedagogia da autonomia: saberes necessários à prática educativa. São Paulo: Paz e Terra.

Matos, E. L. M. y Muggiati, M. M. T. de F. (2007). Pedagogia Hospitalar: a humanização integrando educação e saúde. Petrópolis, RJ: Vozes.

Ministério de Educação (2002). Classe Hospitalar e atendimento Pedagógico domiciliar: estratégias e Orientações. Secretaria de Educação Especial. - Brasília: MEC; SEESP.

Pimenta. S. G. (2009). "Formação de professores: Identidade e saberes da docência”. En: Pimenta, S.G. (Org.) Saberes pedagógicos e atividade docente (pp 15-34). São Paulo: Cortez.

Stake, R. E. (2007). A arte da investigação com estudos de caso. Lisboa: Fundação Calouste Gulbenkian.

Szymanski, H. (org). (2011). A entrevista na pesquisa em educação: a prática reflexiva. V. 4. Brasília: Líber Livro.

Taam, R.(2004). Pelas trilhas da emoção: a educação no espaço da saúde. Maringá: Eduem.

Tardif, M. (2010). Saberes docentes e formação profissional. Petrópolis, RJ: Vozes. Yin, R. K. (2010). Estudo de caso: planejamento e métodos. 4. ed. Porto Alegre: Bookman. 